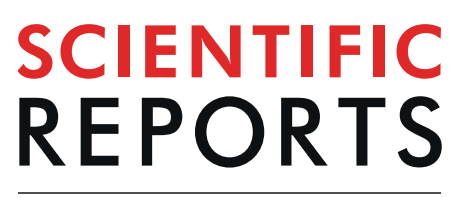

natureresearch

\title{
Genetic engineering of parthenocarpic tomato plants using transient SIIAA9 knockdown by novel tissue-specific promoters
}

\begin{abstract}
Ji-Seong Kim ${ }^{1}$, Kentaro Ezura ${ }^{1}$, Jeongeun Lee ${ }^{1}$, Tohru Ariizumi ${ }^{1,2}$ \& Hiroshi Ezura ${ }^{1,2 *}$
Parthenocarpy is the development of an ovary into a seedless fruit without pollination. The ubiquitous downregulation of SIIAA9 induces not only parthenocarpic fruit formation but also an abnormal vegetative phenotype. To make parthenocarpic transgenic tomato plants without unwanted phenotypes, we found two genes, namely, Solyc03g007780 and Solyc02g067760, expressed in ovary tissue but not in vegetative tissues. Solyc03g007780 was expressed in developing ovaries and anthers. Solyc02g067760 mRNA was detected in whole-flower tissues. The promoters of Solyc03g007780 (Psol80) and Solyc02g067760 (Psol60) predominantly induced the expression of genes in the ovule, placenta, endocarp and pollen and in whole-flower tissues, respectively. Psol80/60-SllAA9i lines, created for SIIAA9-RNA interference controlled by two promoters, successfully formed parthenocarpic fruits without pleiotropic effects in vegetative tissues. Downregulation of SIIAA9, responsible for parthenocarpic fruit formation, was observed in ovules rather than ovaries in the Psol80/60-SIIAA9i lines. Although the weight of parthenocarpic fruits of the Psol80/60-SIIAA9i lines was lower than the weight of pollinated fruits of the wild type (WT), the parthenocarpic fruits presented redder and more saturated colors and higher levels of total soluble solids and titratable acidity than the WT fruits.
\end{abstract}

Due to the importance of tomato fruit as a food, tomato fruit set (the initiation of development of an ovary into fruit) and ripening have been studied for several decades ${ }^{1-4}$. Successful fertilization is essential for fruit set and development followed by the formation of seeds, which are a source of many hormones for cell division and subsequent cell expansion ${ }^{4,5}$. Although cultivated tomatoes have an appropriate flower structure for self-pollination (i.e., the tomato flower has both a pistil and stamens that are similar in length), physical vibration is still needed to complete successful pollination. Additionally, despite the presence of this shaking, failed fruit set can occur under low light or high temperatures ${ }^{6-8}$.

Parthenocarpy, seedless fruit formation without fertilization, is an attractive trait in fruit crops. It can offer improved fruit set and substitute for the effort of artificial pollination, even under adverse conditions. In addition, it can provide specific benefits to the tomato industry, such as the production of paste and juice by facilitating the seed elimination process. Parthenocarpy can be induced by increasing the gibberellin and auxin contents in the ovary, i.e., artificial treatment with gibberellins (GAs) and auxins ${ }^{9-11}$, increased GA content in mutants ${ }^{12}$, and an increase in the indole-3-acetic acid (IAA) content by the iaaM gene ${ }^{13-15}$.

In auxin-related signal transduction during fruit initiation, a complex of auxin/indole-3-acetic acid (Aux/ IAA) and auxin response factor (ARF) protein prevents the expression of auxin-responsive genes. After fertilization, the ovule induces increases in auxin synthesis. Auxin then leads to the degradation of Aux/IAA proteins through the ubiquitin-proteasome pathway ${ }^{16}$. The inactivation of the Aux/IAA function results in the expression of auxin-responsive genes, followed by fruit initiation. In fact, the downregulation of the $A u x / I A A$ transcription factor SIIAA9 activates parthenocarpic fruit set in Micro-Tom ${ }^{17,18}$ as well as other tomato cultivars ${ }^{19,20}$, although the ubiquitous inhibition of SIIAA9 function also causes abnormal phenotypes among vegetative tissues.

The promoter is usually the upstream region of a gene, and it controls where and when the gene is expressed. In genetically modified dicot plants, ubiquitous promoters such as the $35 \mathrm{~S}$ promoter from cauliflower mosaic

${ }^{1}$ Faculty of Life and Environmental Sciences, University of Tsukuba, Tennodai 1-1-1 Tsukuba, Ibaraki, 305-8572, Japan. ${ }^{2}$ Tsukuba Plant Innovation Research Center, University of Tsukuba, Tennodai 1-1-1, Tsukuba, Ibaraki, 3058572, Japan. *email: ezura.hiroshi.fa@u.tsukuba.ac.jp 
a

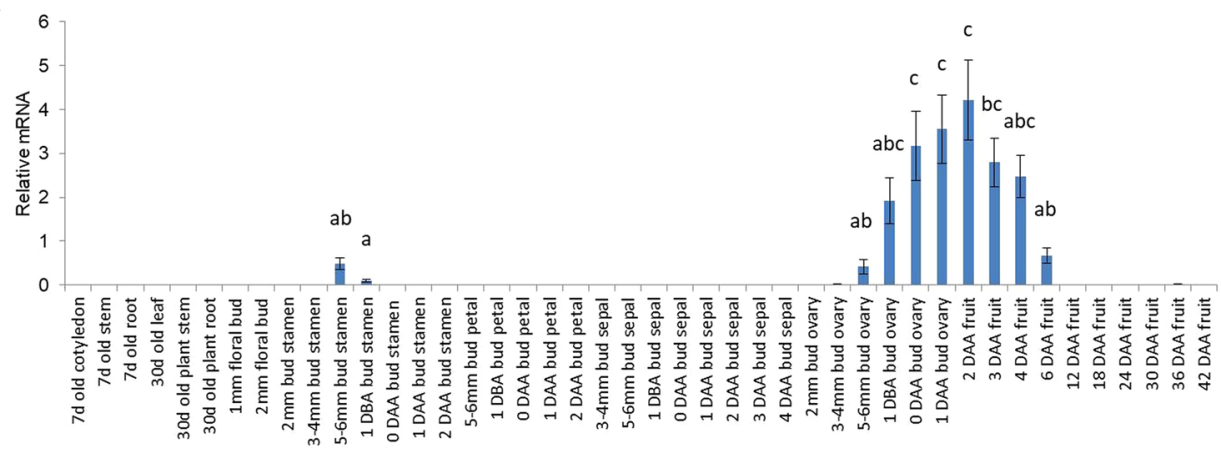

b

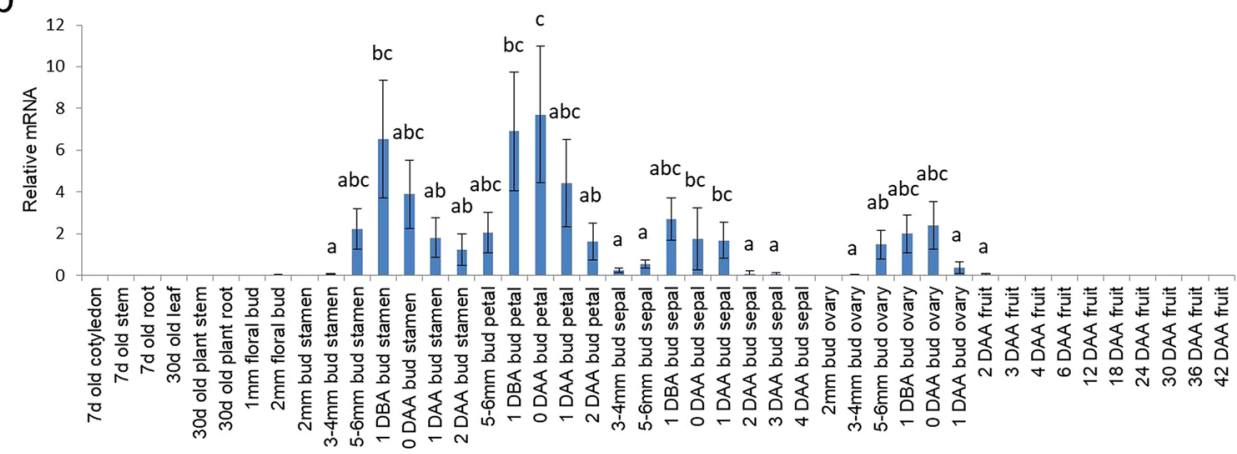

Figure 1. Expression of two candidate genes for promoter development. Relative mRNA levels of (a) Solyc03g007780 and (b) Solyc02g067760. Values are means \pm SDs of three biological replicates. Different letters denote significant differences according to Tukey's HSD test at $\mathrm{p}<0.01$.

virus (P35S) are widely used ${ }^{21}$. However, when ubiquitous promoters are used for the expression of pleiotropic genes such as SIIAA9 or SIDELLA, they also cause unwanted phenotypes ${ }^{18,22}$. To overcome the disadvantages of these ubiquitous promoters, in recent years, many studies have reported the use of tissue-specific promoters in plant parts such as the seeds ${ }^{23-25}$, trichomes ${ }^{26,27}$, tubers ${ }^{28}$, $\operatorname{roots}^{29,30}$, pollen $^{31}$, and petals ${ }^{32}$. However, research on promoters that drive the spatial and temporal expression of genes in reproductive tissues, especially in the ovary, are still rare.

Some researchers have previously reported the development of parthenocarpic tomatoes using a tissue-specific promoter and auxin biosynthesis gene combination in a heterologous system ${ }^{13,15}$. In research on a transgene-harboring construct consisting of an iaaM gene (which is involved in the biosynthesis of indole3-acetic acid) from Pseudomonas syringae pv. savastanoi and the placental/ovule-specific DefH9 promoter from Antirrhinum majus, parthenocarpy was exhibited in transgenic tomatoes.

The objective of this study was to engineer parthenocarpic tomato plants without pleiotropic effects on vegetative tissues. To do so, we developed new, flower-specific promoters from tomatoes, with a special focus on the ovary tissues. Our transgenic plant lines created with novel, specific promoters and a SIIAA9-RNA interference (RNAi) construct showed a vegetative phenotype similar to that of the wild type, and they also successfully formed parthenocarpic fruits.

\section{Results and Discussion}

Expression of Solyc03g007780 and Solyc02g067760 in various tissues. The first objective of our study was to develop an ovary-specific promoter. To identify the tissue-specific genes expressed in ovary tissues but not in vegetative tissues, we used RNA-seq data from 27 tissues of the tomato dwarf cultivar 'Micro-Tom' provided in a previous report ${ }^{33}$. Among the 505 genes specifically detected in the ovary samples, twenty-nine genes were selected and identified by comparison with an EST library representation of the Sol Genomics Network. Solyc03g007780 and Solyc02g067760 were selected by quantitative reverse transcription (qRT)-PCR analysis for further study.

Solyc03g007780 was not expressed in vegetative tissues such as the leaf, stem, and root of 7- and 30-day-old plants, but it was expressed in the ovaries at various time points and in the stamens when they reached a length of 5-6 $\mathrm{mm}$ and 1 day before anthesis (DBA) (Fig. 1a). In developing ovaries and pollinated ovaries (referred to as fruits in Fig. 1), the expression of Solyc03g007780 was initiated in 5-6 mm buds, and it gradually increased until 2 days after anthesis (DAA) and decreased from 3 DAA to 6 DAA. A previous report revealed that Solyc03g007780, which was designated an ovule-secreted protein (OSP), was expressed in ovules at a high level but was rarely expressed in other fruit or vegetative tissues, with the exception of fruits entering the ripening stage, in Solanum pimpinellifolium $^{34}$. However, these expression data showed little difference in comparison with our data (e.g., the stamen in our data and the fruits entering the ripening stage in their data). 
Solyc02g067760 was expressed in whole-flower tissues but not in vegetative tissues in this study (Fig. 1b). In the stamens and petals, Solyc02g067760 mRNA was detected in the 5-6 mm buds, reached its peak level 1 DBA and 0 DAA, respectively, and then decreased. Its expression in the sepals gradually increased between the 3-4 mm and 1 DBA stages of buds and decreased thereafter. In developing ovaries and pollinated ovaries, the transcription of Solyc02g067760 initiated in the 5-6 mm buds, increased until 0 DAA, and stopped after 2 DAA.

GUS activity of the promoters of Solyc03g007780 and Solyc02g067760. To develop tissue-specific promoters based on tissue-specific expressed genes, namely, Solyc03g007780 and Solyc02g067760, a 2002 bp region from the start codon of Solyc03g007780 (Psol80) or a 1996 bp region from Solyc02g067760 (Psol60) was amplified and cloned into $\beta$-glucuronidase (GUS) expression vectors (Supplementary Fig. S1). At least two independent $\mathrm{T}_{2}$ lines per construct were used for the GUS histochemical analysis, and lines harboring the same construct showed the same GUS staining pattern.

In comparison, tomato plants transformed with P35S-GUS, the binary vector constituting the GUS gene under a control of the constitutive CaMV 35S promoter (P35S), showed ubiquitous GUS staining, in contrast to wild type (WT) plants, which exhibited no GUS activity (Fig. 2a). The tomato plants containing the promoter of either the Solyc03g007780-GUS (Psol80-GUS) or Solyc02g067760-GUS (Psol60-GUS) construct exhibited tissue-specific GUS staining devoid of GUS activity in the vegetative tissues. In Psol80-GUS lines, GUS activity was observed in anther tissue at the anthesis stage and the seeds of 18-day-old fruits (Fig. 2a). In Psol60-GUS lines, GUS staining was observed in the entire flower and 18-day-old fruits.

According to our qRT-PCR results, both genes were expressed in the ovaries before and after the anthesis stage (Fig. 1), followed by no expression beginning 6 DAA (Solyc03g007780) or 2 DAA (Solyc02g067760). However, in the seeds and seed-surrounding tissues of fruits in the WT as well as all promoter-GUS plants, we observed a pale blue color, despite the use of modified methods to reduce intrinsic GUS-like activity according to previous reports ${ }^{35,36}$. The reproductive organs of tomatoes, such as the pericarp, seed coat and embryo, have unexpected GUS-like activity ${ }^{37}$. Additionally, GUS protein is very stable in cells, and its half-life is up to $50 \mathrm{~h}$ in living cells ${ }^{38}$. Therefore, to reconfirm the GUS activity controlled by PSol80 and PSol60 in ovaries developing into fruits, the mRNA of the GUS gene was measured by qRT-PCR. In the Psol80/60-GUS lines, the GUS gene was expressed in the 0 DAA floral buds and not detected in the leaf, 3-4 mm bud, 6 DAA fruit, 18 DAA green fruit, or 40 DAA red fruit (Supplementary Fig. S2a). Although the expression level of the GUS gene of the Psol80/60-GUS lines was relatively low compared with that of the P35S-GUS lines, the expression patterns corresponded to those of Solyc03g007780 and Solyc02g067760 (Fig. 1). For more detailed observations, the sectioned ovaries at 2 and 4 DAA and the anthers at anthesis were subjected to GUS staining. In contrast to the results for the WT, tissue-specific GUS staining was observed in the Psol80/60-GUS lines (Fig. 2b). In the Psol80-GUS lines, GUS staining was observed in pollen, ovules, and a small part of the placenta and endocarp surrounding the ovule. In the Psol60-GUS lines, GUS activity was detected in anthers, pollen, and ovaries. The mRNA of GUS was also detected in the 0 DAA ovaries from P35S-GUS and Psol80/60-GUS lines but not in those from the WT (Supplementary Fig. S2b). The results of the promoter GUS assay, taken together, demonstrated that both Psol80 and Psol60 induced tissue- and developmental stage-specific expression before and after anthesis.

Development of parthenocarpic transgenic tomato plants. The downregulation or loss of function of the Aux/IAA transcription factor SIIAA9, a negative regulator of the auxin response, resulted in the development of parthenocarpic fruits ${ }^{17,18}$. However, due to the ubiquitous role of SIIAA9, the constitutive knockdown or knockout of this gene also results in abnormal vegetative phenotypes, such as fused leaves with simple lobes. To obtain parthenocarpic tomato plants without the pleiotropic effect on vegetative tissues, Psol80 or Psol60 was used to drive the ovary-specific transcription of the RNAi constructs for SIIAA9 knockdown (Supplementary Fig. S1). To prevent off-target effects on other Aux/IAA genes, identical SlIAA9 mRNA region that verified targeting accuracy in a previous report ${ }^{18}$ was selected through further confirmation by the BLAST algorithm of the Sol Genomics Network. Through Agrobacterium-mediated transformation into 'Micro-Tom' cultivars, three independent RNAi lines (lines 4-17, 4-23, and 4-25) for SlIAA9 downregulation by Psol80 (Psol80-SIIAA9i) and two lines (lines 6-10 and 6-18) for SlIAA9 downregulation by Psol60 (Psol60-SlIAA9i) were obtained.

First, we evaluated parthenocarpic fruit formation after emasculation. In our experiment, growing ovary followed by color change from green to reddish was considered as a fruit. Both the Psol80-SIIAA9i and Psol60-SIIAA9i lines successfully formed parthenocarpic fruits, similar to the iaa9-3 line ${ }^{17}$, SlIAA9 mutant with malfunction of SIIAA9 protein, used as a control line with parthenocarpy (Fig. 3). On the other hand, most emasculated flowers of the WT withered and fell within 2 weeks without developing into fruits. Only very few unpollinated WT ovaries (approximately $2 \%$ of the unpollinated ovaries) developed into abnormal fruits with an orange color, spongy pericarp, and weight under $0.3 \mathrm{~g}$. The percentage of parthenocarpic fruit formation was $63 \%$ in the iaa9-3 mutant and ranged from 62 to $68 \%$ in the Psol80-SlIAA9i lines (4-17, 23, and 25) (Table 1). The Psol60-SIIAA9i lines showed relatively low parthenocarpic efficiency, measuring 40\% (6-10) and 44\% (6-18), compared with the efficiency of other tested lines. When two flowers per flower truss were emasculated, the weight of parthenocarpic fruits from the iaa9-3 mutant was similar to that of fruits from pollinated ovaries of the WT, whereas the weight of the parthenocarpic fruits of the Psol80-SIIAA9i lines was up to $45 \%$ of that of the pollinated fruits of the WT. Furthermore, the parthenocarpic fruits of the Psol60-SlIAA9i lines exhibited a much lower weight than the pollinated fruits of the WT (up to approximately $20 \%$ ).

Previous researchers revealed that the pollen and ovules of SIIAA9-downregulated lines were fertile, although a small percentage of pollinated flowers developed into seeded fruits (35\%) when an SIIAA9-downregulated line was used as the female recipient ${ }^{18}$. During self-pollination of the iaa9-3 mutant, we also observed that some fruits from pollinated ovaries did not have any seeds despite several rounds of artificial pollination. To determine whether parthenocarpic fruit set in Psol80/60-SlIAA9i lines also has an effect on seeded fruit formation, we measured the efficiency of fruit 
a

WT

untreated

WT
Psol80-GUS

Leaf

\section{Root}
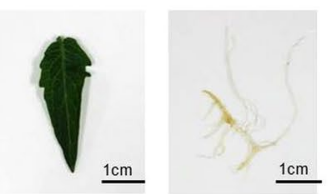

lcm

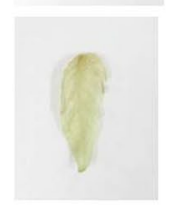

Psol60-GUS
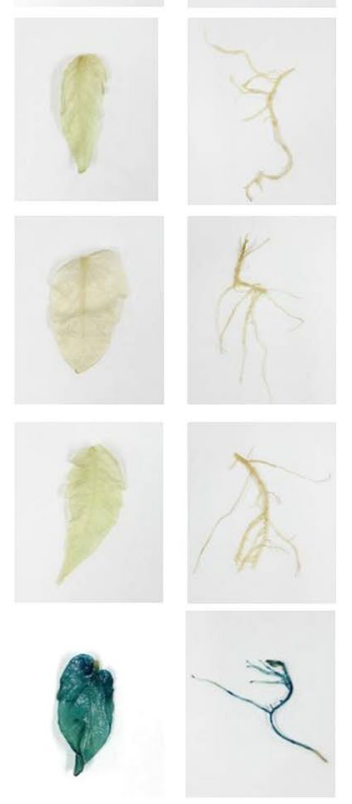

$3-4 \mathrm{~mm}$ bud
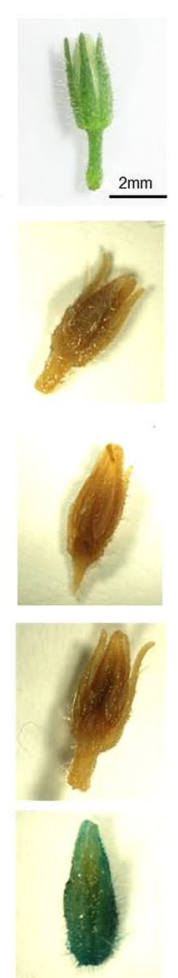

Flower
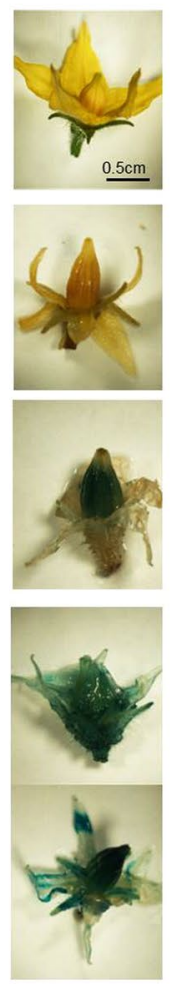

18 day fruit

40 day fruit
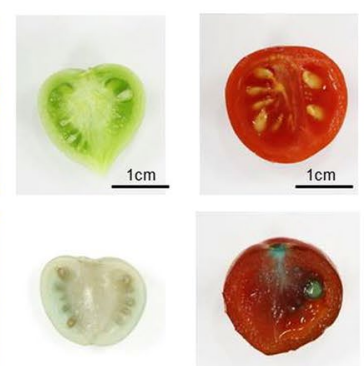

$1 \mathrm{~cm}$
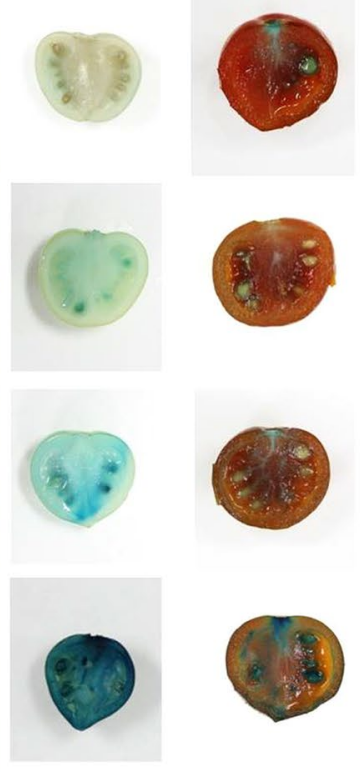

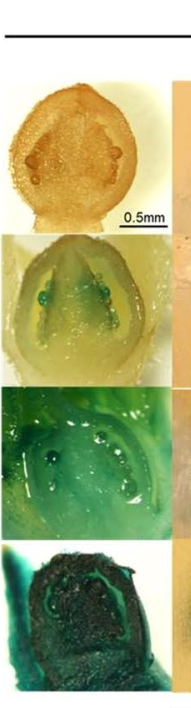

Ovary
2 DAA
4 DAA
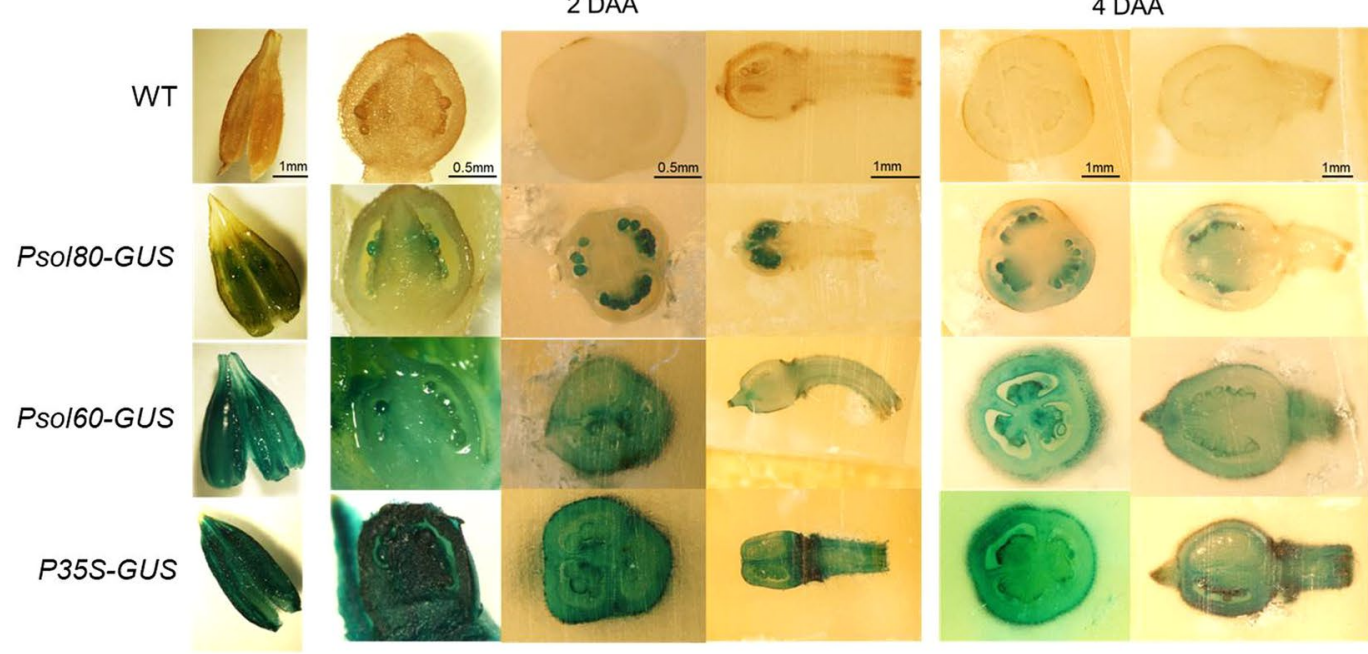

Paraffin section

Figure 2. GUS histochemical assays of transgenic tomato harboring a promoter-GUS expression vector. (a) Images of the leaf, root, floral bud, flower, and fruit. (b) A stamen and paraffin-sectioned ovary under a dissecting microscope. Wild type (WT), promoter of Solyc03g007780-GUS line (Psol80-GUS), promoter of Solyc02g067760-GUS line (Psol60-GUS), and CaMV 35 S promoter-GUS (P35S-GUS).

formation and fruit weight using six self-pollinated flowers per plant. While most of the pollinated ovaries of the WT (95\%) developed into seeded fruits, i.e., fruits resulting from pollination, the iaa9-3 mutant produced a small number of seeded fruits (67\%) with fewer seeds than the pollinated fruits of the WT (Table 1). However, the Psol80/60-SlIAA9i lines showed efficiencies of seeded fruit formation and seed number per fruit that were similar to those of the WT. These results indicated that the Psol80-SIIAA9i and Psol60-SILAA9i lines showed facultative parthenocarpy, in contrast to the iaa9-3 mutant. Previous researchers reported that the early pollinated fruits of SIIAA9-downregulated lines were larger than those of the $\mathrm{WT}^{39}$. However, the weight of pollinated mature fruits from SlIAA9-inhibited lines (Psol80/60-SlIAA9i lines and iaa9-3 mutant) was similar to that of pollinated fruits of the WT (Table 1). 
a

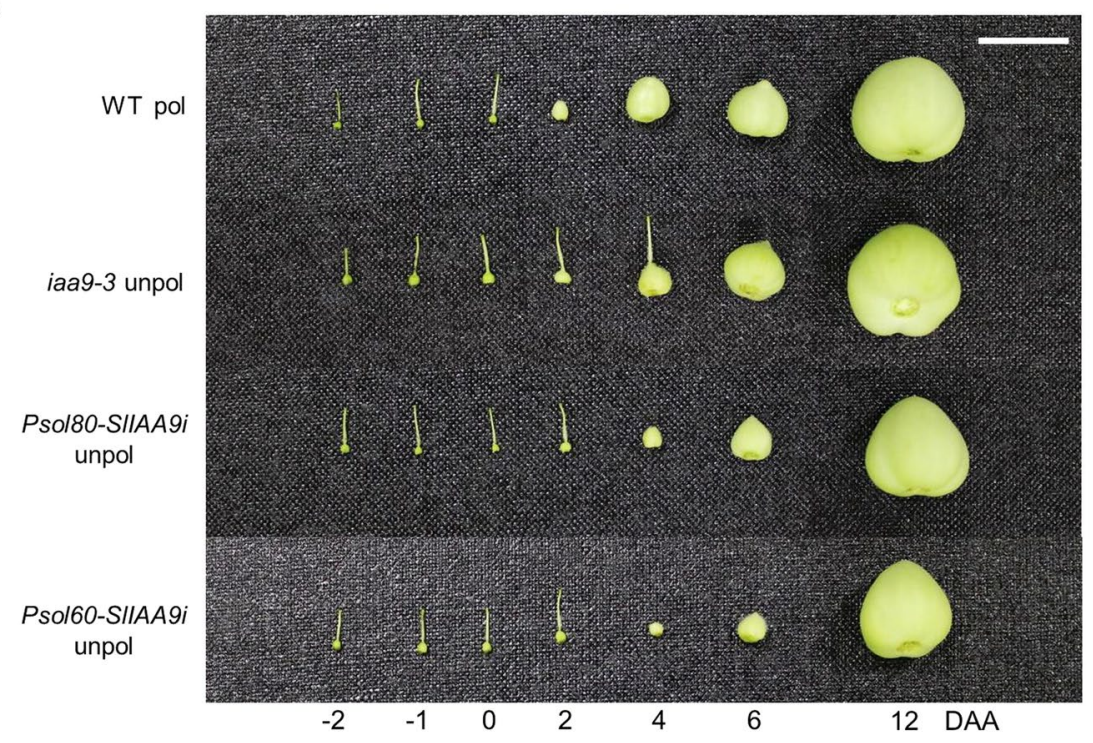

$\mathrm{b}$

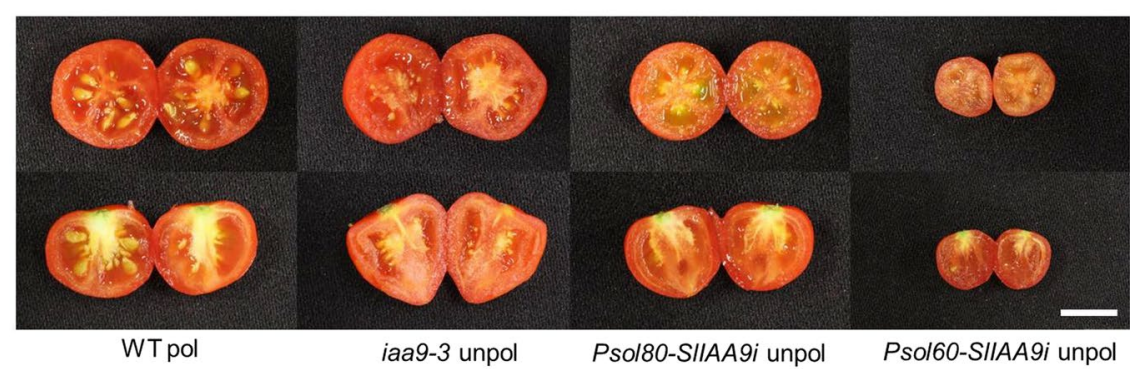

Figure 3. Representative fruit formation of transgenic lines. (a) Ovaries during early fruit development. (b) Mature red fruit. Pollinated wild type (WT pol), iaa9-3 mutant (iaa9-3), transgenic tomato line with an SlIAA9RNA interference construct controlled by the Solyc03g007780 promoter (Psol80-SlIAA9i) and Solyc02g067760 promoter (Psol60-SlIAA9i). Bar $=1 \mathrm{~cm}$.

Engineered parthenocarpic tomato plants exhibit a WT-like vegetative phenotype. In a previous report, the inhibition of SIIAA9 also caused altered vegetative tissue morphology, such as fused leaves, long internodes and increased lateral shoot numbers, corresponding to ubiquitous expression of SIIAA $9^{17,18}$. In this study, while the iaa9-3 mutant showed an abnormal plant form with a sparse leaf arrangement, the Psol80/60-SlIAA9i lines (4-17, 4-23, 4-25, 6-10, and 6-18) presented plant forms similar to those of the WT (Fig. 4a). To present the difference in plant form numerically, we counted the number of compound leaves and flower trusses on 50-day-old plants. All Psol80-SIIAA9i and Psol60-SIIAA9i lines formed similar numbers of compound leaves and flower trusses compared to those of WT (Fig. 4b). However, the iaa9-3 mutant formed significantly fewer flower trusses and compound leaves. In addition, the WT and all Psol80/60-SlIAA9i lines exhibited pinnately compound leaves with lobed leaflets, whereas the iaa9-3 mutant formed fused leaves with simple lobes (Fig. 4c). Because the downregulated level of SIIAA9 in leaves showed a positive correlation with the severity of altered leaf morphology ${ }^{18}$, we also examined the mRNA level of SIIAA9 in leaves to explain the normal leaf morphology of the Psol80/60-SIIAA9i lines. Consistent with the WT-like leaf phenotype, the Psol80/60-SlIAA9i lines showed SIIAA9 mRNA levels similar to those of the WT, in contrast to the iaa9-3 mutant, which presented no intact SIIAA9 mRNA in leaves (Fig. 4d). Furthermore, Solyc03g007780 and Solyc02g067760 expression was also not detected in the expanding leaves of the corresponding transgenic lines (Supplementary Fig. S3). These results suggested that the mRNA level of SIIAA9 was not affected by SIIAA9i in leaves of the Psol80/60-SIIAA9i lines.

Tissue specific downregulation of SIIAA9 is responsible for parthenocarpic fruit formation in Psol80/60-SIIAA9i lines. Knockdown of SIIAA9 mRNA mimics increased auxin followed by subsequent parthenocarpic fruit formation ${ }^{16,18}$. In unpollinated ovaries, SIIAA9 mRNA was more strongly distributed in the ovule and placenta than in other ovary tissues ${ }^{39}$, implying that the transcript level of SlIAA9 in those tissues is important for parthenocarpic fruit set by SIIAA9 inhibition. Consistent with this interpretation, increased IAA in the placental/ovule tissue was sufficient for induction of parthenocarpic fruit set ${ }^{14,15}$. In the present study, Psol80 and Psol60 also induce the expression of the genes in ovules and placenta (Fig. 2b). Therefore, we assessed the mRNA level of SIIAA9 in ovules of Psol80/60-SIIAA9i lines. The level of SlIAA9 mRNA was significantly or slightly lower in the ovules of the Psol80-SIIAA9i lines and Psol60-SIIAA9i lines, respectively, than in the ovules 


\begin{tabular}{|c|c|c|c|c|c|}
\hline & Lines & $\begin{array}{l}\text { Fruit set (\%; No. } \\
\text { of fruits/flower) }\end{array}$ & Weight $(\mathrm{g})^{\dagger}$ & Yield/plant ${ }^{\ddagger c}(\mathrm{~g})$ & \\
\hline \multirow{8}{*}{ Emasculation $^{\mathrm{a}}$} & WT pol & $95(97 / 102)$ & $2.17 \pm 0.95$ & $36.6 \pm 7.92^{c}$ & \\
\hline & WT unpol & $2(3 / 134)$ & - & - & \\
\hline & 4-17 unpol & $66(126 / 191)$ & $0.78 \pm 0.56 *$ & $24.5 \pm 4.84^{\mathrm{b}}$ & \\
\hline & 4-23 unpol & $62(114 / 183)$ & $0.85 \pm 0.45 *$ & $25.3 \pm 3.73^{\mathrm{b}}$ & \\
\hline & 4-25 unpol & $68(144 / 213)$ & $0.97 \pm 0.54 *$ & $27.8 \pm 3.07^{\mathrm{bc}}$ & \\
\hline & 6-10 unpol & $40(40 / 101)$ & $0.38 \pm 0.17$ * & $6.7 \pm 4.69^{\mathrm{a}}$ & \\
\hline & 6-18 unpol & $44(70 / 158)$ & $0.43 \pm 0.19 *$ & $8.7 \pm 2.12^{\mathrm{a}}$ & \\
\hline & iaa9-3 unpol & $63(79 / 126)$ & $2.01 \pm 1.23$ & $26.8 \pm 3.61^{\mathrm{bc}}$ & \\
\hline \multirow{8}{*}{ Pollination ${ }^{\mathrm{b}}$} & Lines & $\begin{array}{l}\text { Fruit set (\%; No. } \\
\text { of fruits/flower) }\end{array}$ & Weight $(\mathrm{g})^{\dagger}$ & Seed set (\%) & $\begin{array}{l}\text { No. of seeds/ } \\
\text { fruit }(n=12)^{\dagger}\end{array}$ \\
\hline & WT pol & $96(57 / 59)$ & $3.56 \pm 0.81$ & $100(57 / 57)$ & $38.0 \pm 9.77$ \\
\hline & 4-17 pol & $96(65 / 68)$ & $3.51 \pm 0.79$ & $100(65 / 65)$ & $31.9 \pm 12.26$ \\
\hline & \begin{tabular}{|l|}
$4-23$ pol \\
\end{tabular} & $95(62 / 65)$ & $3.46 \pm 0.80$ & $98(61 / 62)$ & $37.9 \pm 11.03$ \\
\hline & 4-25 pol & $94(51 / 54)$ & $3.31 \pm 0.83$ & $100(51 / 51)$ & $33.9 \pm 11.12$ \\
\hline & 6-10 pol & $94(50 / 53)$ & $3.67 \pm 0.82$ & $100(50 / 50)$ & $37.0 \pm 9.77$ \\
\hline & 6-18 pol & $95(55 / 58)$ & $3.32 \pm 0.96$ & $100(55 / 55)$ & $33.6 \pm 7.73$ \\
\hline & iaa9-3 pol & $58(55 / 95)$ & $3.35 \pm 1.57$ & $67(37 / 55)$ & $24.8 \pm 9.02^{*}$ \\
\hline
\end{tabular}

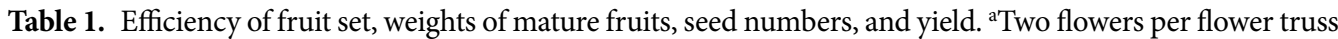
were emasculated. ${ }^{b}$ Six flowers per plant were artificially pollinated. ${ }^{c}$ All the flowers from the 4 th flower truss were pollinated in the WT or emasculated in Psol80/60- SlIAA9i and the iaa9-3 mutant for 4 weeks. ${ }^{\dagger}$ Each data point represents the mean \pm standard deviation. *Asterisks indicate significant differences relative to WT pol $(* \mathrm{P}<0.05$; Student's t-test). - Not measured. ${ }^{\ddagger}$ Each data point represents the mean \pm standard deviation $(\mathrm{n}=4-6$ plants). Different letters denote significant differences between factors according to Tukey's HSD test at $\mathrm{p}<0.01$.

of the unpollinated or pollinated WT (Fig. 5a). This result suggested that the parthenocarpic fruit formation was induced by downregulation of SIIAA9 mRNA -in the Psol80/60-SlIAA9i lines.

In the assay of SIIAA9 transcript levels in ovaries, the transcript level of SIIAA9 in unpollinated ovaries of the WT continuously decreased between 0 and 6 DAA without ovary growth (Fig. 5b). However, the level dramatically increased 2 DAA and remained at that level with ovary development into fruit by pollination or 2,4-D treatment. The level of SIIAA9 mRNA in developing ovaries of the Psol80/60-SlIAA9i lines was not increased compared with that of unpollinated ovaries of the WT between 0 and 4 DAA, but it rapidly increased 6 DAA in the Psol80-SlIAA9i lines or 12 DAA in the Psol60-SIIAA9i lines.

Surprisingly, an obvious decrease in SIIAA9 mRNA level by SIIAA9 RNAi in ovaries of the Psol80/60-SIIAA9i lines was not observed. To describe the insufficient downregulation of SIIAA9 in ovaries, the activity of Psol80/60 had to be considered. As shown in Fig. 2b and Supplementary Fig. S2b, Psol80 induced the transcription of the gene in the ovule and adjacent tissues, which occupied a small portion of the entire ovary (containing the columella, ovary wall, placenta, and ovule), resulting in low expression in the entire ovary. Psol60 also conferred much lower expression to the controlled gene compared with P35S. These results implied that the distribution or the amount of SIIAA9 dsRNA expressed by Psol80/60 was not sufficient to cause a remarkable decrease in SIIAA9 $m R N A$ level in the entire developing ovary. Meanwhile, despite the development of ovaries into fruits in the Psol80/60-SIIAA9i lines (Fig. 3A), the increase in SIIAA9 mRNA level was delayed until 6 DAA in the Psol80-SlIAA9i lines and 12 DAA in the Psol60-SlIAA9i lines. These expression patterns showed an inverse correlation with the expression pattern of Solyc03g007780 in the pollinated and unpollinated ovaries of WT and Solyc02g067760 in the unpollinated ovaries of WT, reflecting the activity of each promoter (Fig. 1, Supplementary Fig. S4). Solyc03g007780 was expressed considerably from 0 DAA to 4 DAA, and at the same time, the SlIAA9 mRNA level was not increased. However, at the time point when the expression of Solyc03g007780 was extremely reduced (6 DAA), the transcripts of SIIAA9 mRNA increased. The same expression pattern was observed in ovaries 12 DAA in the Psol60-SIIAA9i lines. These results suggest that the increase of SlIAA9 mRNA by ovary development was partially suppressed during RNAi constructs for SIIAA9 knockdown expressed by two promoters.

According to a previous report, the percentage of parthenocarpy in SIIAA9-downregulated tomato lines was negatively correlated with the level of SIIAA9 mRNA $^{18}$. In our research, we also observed that parthenocarpic lines with lower levels of SIIAA9 mRNA in ovules showed a higher efficiency of parthenocarpy (Table 1, Fig. 5a). In addition, we found a negative correlation between the transcript level of SIIAA9 in ovules and the weight of the mature fruits; i.e., strongly downregulated lines showed larger fruit formation (Table 1, Fig. 5a,).

Fruit quality and yield of parthenocarpic fruits in Psol80/60-SIIAA9i lines. We also examined the fruit quality and yield of parthenocarpic fruits of the SIIAA9-inhibited lines. There was no significant difference in $\mathrm{pH}$ between the parthenocarpic fruits of SIIAA9-inhibited lines and the pollinated fruits of the WT. However, in the titratable acidity (TA) assay, parthenocarpic fruits showed increased TA compared with pollinated fruits of the WT (Table 2). While the parthenocarpic fruits of the Psol80-SlIAA9i lines and iaa9-3 mutant presented slightly increased TA, those of the Psol60-SlIAA9i lines had much higher TA. Although the value of TA is mainly 
a
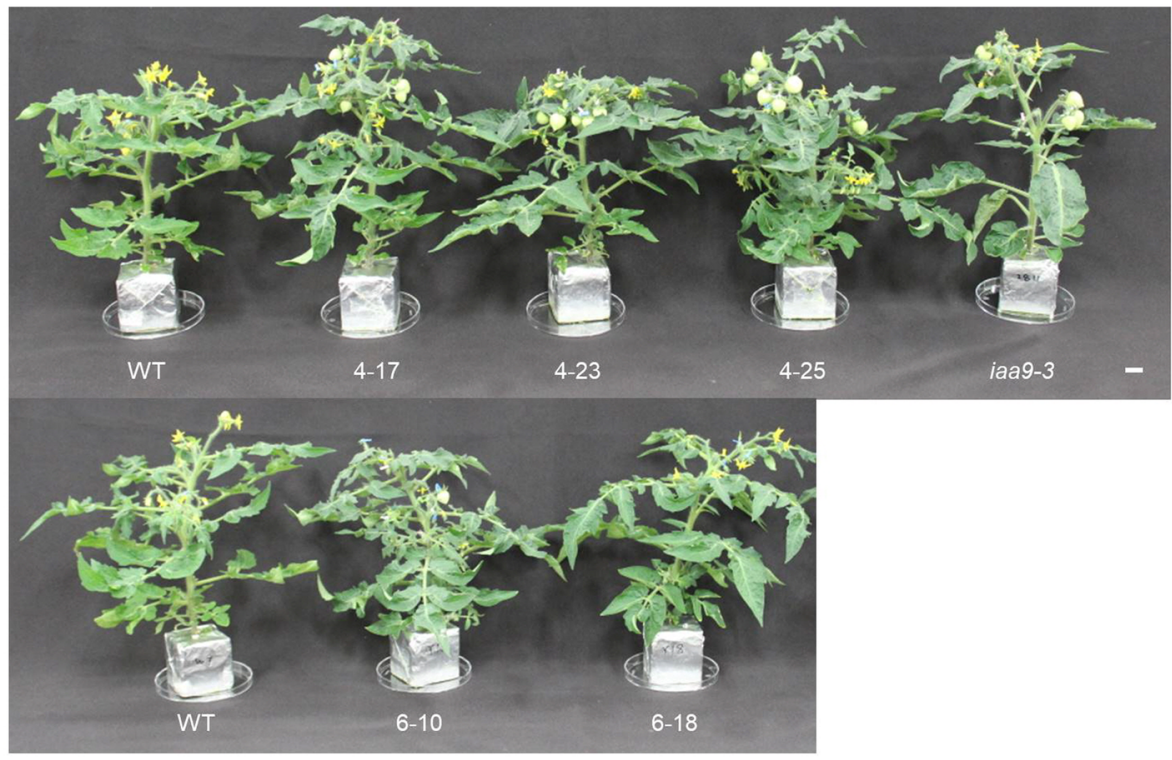

b
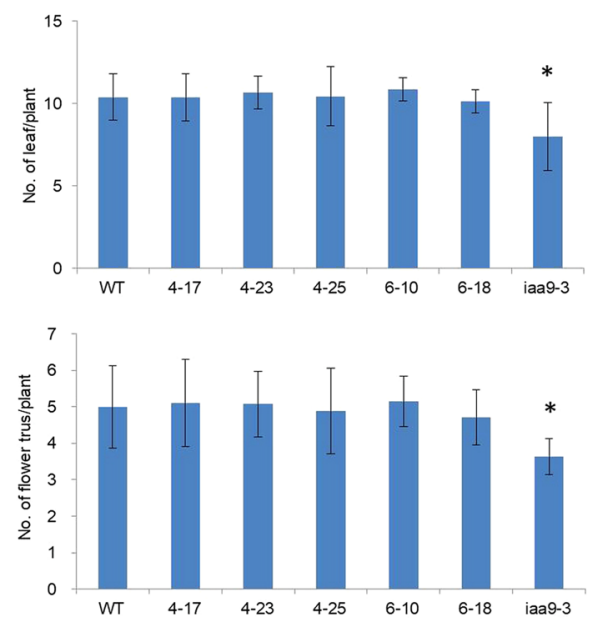

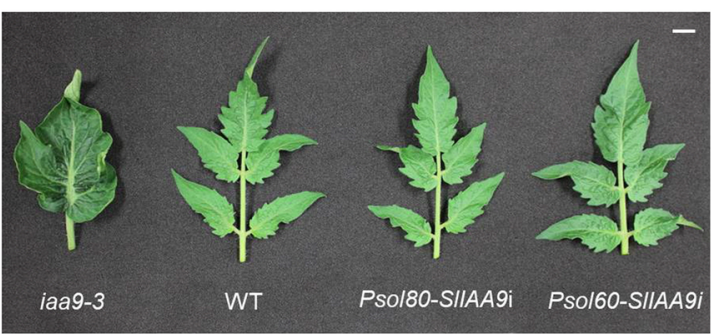

d

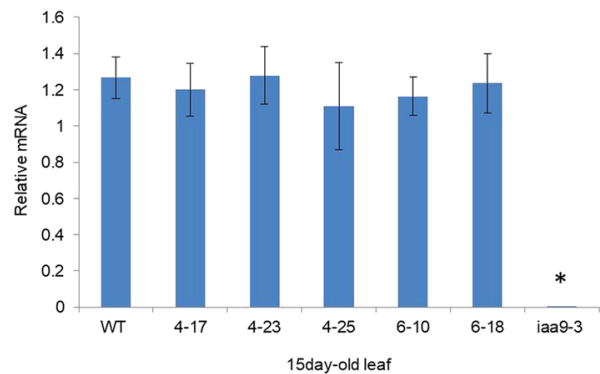

Figure 4. Vegetative phenotype of transgenic lines. (a) Plant form of 50-day-old plants. (b) Nos. of compound leaves and flower trusses. Values are means \pm SDs of 9 plants. Asterisks indicate significant differences from the WT $(\mathrm{P}<0.05$; Student's t-test). (c) Comparison of leaf morphologies. (d) Expression levels of SlIAA9 in expanding leaves (15 days old). The values are the means \pm SDs of 5 biological replicates. Wild type (WT), iaa93 mutant (iaa9-3), Psol80-SlIAA9i lines (4-17, 23 and 25), and Psol60-SlIAA9i lines (6-10 and 18).

determined by concentrations of citric acid, malic acid, and phosphate in tomato fruits, phosphate concentrations showed no difference with between cultivars with various $\mathrm{TA}^{40}$. Therefore, the higher TA suggests that the parthenocarpic fruits had high acid concentrations compared with that in the pollinated fruits of the WT.

Parthenocarpic tomato fruits induced by increased IAA contents in the ovules have similar fruit weights, slightly increased levels of total soluble solids (TSS) compared with those of pollinated fruits of the WT ${ }^{13}$. The parthenocarpic fruits of iaa9-3 mutant also showed higher levels of total soluble solids (TSS) than the fruits of the WT (Table 2). In particular, low-weight parthenocarpic fruits from the Psol80/60-SlIAA9i lines exhibited much higher TSS levels than pollinated fruits of the WT. Generally, the Psol80/60-SIIAA9i lines formed lower-weight parthenocarpic fruits than the iaa-3 mutant line, and the fruits of these lines had higher TA and TSS values. This result also suggested that low-weight parthenocarpic fruits had higher TA and TSS values.

In the evaluation of fruit color, the parthenocarpic fruits of the iaa9-3 mutant and Psol80/60-SlIAA9i lines presented higher chroma and hue values, indicating more color saturation and a redder color than observed for the pollinated WT fruits ${ }^{41}$ (Table 3 ). The more saturated and redder color of parthenocarpic fruits in the Psol80/60-SIIAA9i lines also suggested that the fruits of these lines were induced by successful SlIAA9 inhibition, similar to the case of parthenocarpic fruits in the iaa9-3 mutant. In addition, since lycopene is the main carotenoid responsible for the red color of tomato fruits ${ }^{42}$, we also measured the lycopene and $\beta$-carotene contents in 

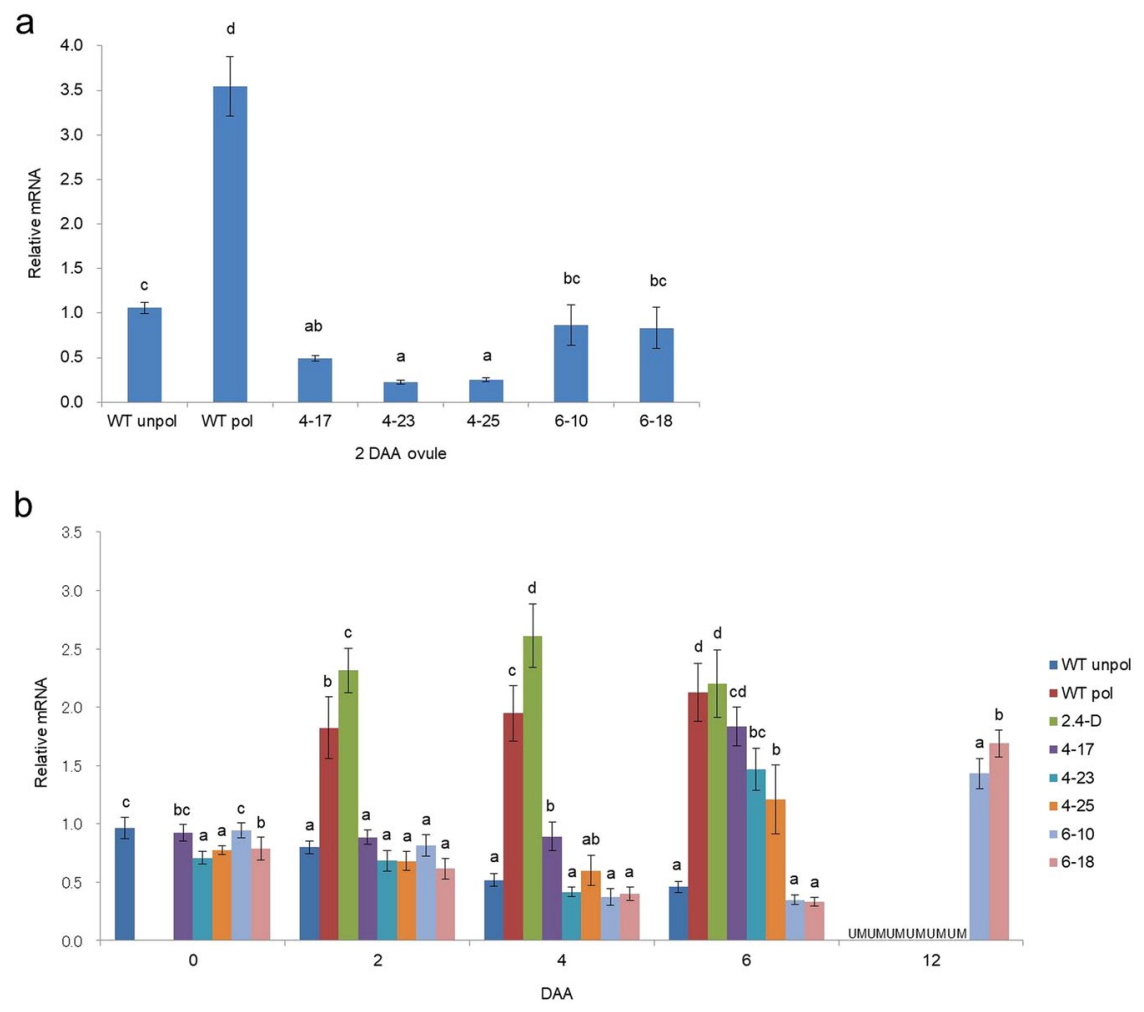

Figure 5. Expression levels of SlIAA9. (a) Ovules 2 DAA. (b) Ovaries $0,2,4,6$ and 12 days after anthesis (DAA). Unpollinated (WT unpol), pollinated (WT pol), and 2,4-dichlorophenoxyacetic acid-treated (2,4D) ovaries of the wild type. Unpollinated ovaries of Psol80-SlIAA9i lines (4-17, 23 and 25), Psol60-SlIAA9i lines (6-13 and 18), and the iaa9-3 mutant (iaa9-3). Values are means \pm SDs from three biological replicates. Different letters denote significant differences according to Tukey's HSD test at $p<0.01$ at each time point. UM indicates unmeasured.

\begin{tabular}{|l|l|l|l|l|l|}
\hline Lines & $\mathbf{p H}$ & TA (\%) & TSS & $\begin{array}{l}\boldsymbol{\beta} \text {-carotene } \\
(\mu \mathrm{g} / \mathrm{g})\end{array}$ & $\begin{array}{l}\text { Lycopene } \\
(\mu \mathrm{g} / \mathrm{g})\end{array}$ \\
\hline WT pol & $3.76 \pm 0.05^{\mathrm{ab}}$ & $0.079 \pm 0.0073^{\mathrm{a}}$ & $5.6 \pm 0.12^{\mathrm{a}}$ & $26.26 \pm 3.01^{\mathrm{a}}$ & $90.68 \pm 5.14^{\mathrm{a}}$ \\
\hline $4-17$ & $3.66 \pm 0.10^{\mathrm{a}}$ & $0.099 \pm 0.0074^{\mathrm{bc}}$ & $7.8 \pm 0.55^{\mathrm{b}}$ & $25.16 \pm 2.35^{\mathrm{a}}$ & $89.83 \pm 3.99^{\mathrm{a}}$ \\
\hline $4-23$ & $3.80 \pm 0.11^{\mathrm{ab}}$ & $0.091 \pm 0.0083^{\mathrm{ab}}$ & $7.2 \pm 0.92^{\mathrm{b}}$ & $21.86 \pm 1.87^{\mathrm{a}}$ & $87.61 \pm 5.02^{\mathrm{a}}$ \\
\hline $4-25$ & $3.72 \pm 0.07^{\mathrm{ab}}$ & $0.088 \pm 0.0077^{\mathrm{ab}}$ & $6.8 \pm 0.80^{\mathrm{ab}}$ & $34.87 \pm 4.99^{\mathrm{a}}$ & $99.41 \pm 2.94^{\mathrm{a}}$ \\
\hline $6-10$ & $3.72 \pm 0.04^{\mathrm{ab}}$ & $0.115 \pm 0.0087^{\mathrm{c}}$ & $9.9 \pm 0.62^{\mathrm{c}}$ & $34.40 \pm 17.23^{\mathrm{a}}$ & $89.72 \pm 18.03^{\mathrm{a}}$ \\
\hline $6-18$ & $3.70 \pm 0.01^{\mathrm{ab}}$ & $0.116 \pm 0.0082^{\mathrm{c}}$ & $10.0 \pm 0.42^{\mathrm{c}}$ & $27.13 \pm 7.00^{\mathrm{a}}$ & $92.80 \pm 5.54^{\mathrm{a}}$ \\
\hline iaa9-3 & $3.84 \pm 0.05^{\mathrm{b}}$ & $0.084 \pm 0.0043^{\mathrm{ab}}$ & $6.9 \pm 0.19^{\mathrm{ab}}$ & $39.07 \pm 8.36^{\mathrm{a}}$ & $98.37 \pm 6.27^{\mathrm{a}}$ \\
\hline
\end{tabular}

Table 2. Total soluble solids (TSS, ${ }^{\circ}$ Brix), titratable acidity (TA), and $\beta$-carotene and lycopene contents in mature fruits. Each data point represents the mean \pm standard deviation $(n=5)$. Different letters denote significant differences between factors according to Tukey's HSD test at $\mathrm{p}<0.01$.

the parthenocarpic fruits of SIIAA9-inhibited lines (Table 2). However, there was no difference in $\beta$-carotene or lycopene content compared with the content in pollinated fruits from the WT. Additionally, the L* values, which express the lightness of fruits and have positive correlations with total carotenoid and lycopene contents ${ }^{43}$, did not show significant differences between the WT and SIIAA9-inhibited lines (Table 3). These results suggested that the saturated red color of parthenocarpic fruits in the SIIAA9-inhibited line was caused by other pigments, not a high lycopene content.

To compare the yield of parthenocarpic fruits of Psol80/60-SlIAA9i lines to that of pollinated fruits of the WT, all the flowers from the 4 th flower truss were pollinated or emasculated for 4 weeks. The yield of the iaa9-3 mutant was up to $73 \%$ of that of the WT, whereas that of the Psol80-SIIAA9i and Psol60-SIIAA9i lines was up to $76 \%$ and $24 \%$, respectively, despite these lines expressing a WT-like leaf number and morphology (Table 1, Fig. 4b,c). This change in yield is thought to be the result of relatively low parthenocarpic fruit set efficiency and fruit weight due to insufficient downregulation of SIIAA9 in the ovule.

The objective of this study was to make parthenocarpic tomato plant without abnormal vegetative phenotype. In this study, the promoters of Solyc03g007780 and Solyc02g067760 induced tissue specific expression of genes. 


\begin{tabular}{|l|l|l|l|l|}
\hline Lines & Color $\mathrm{L}^{*}$ & $\mathrm{a}^{*}$ & Chroma & Hue \\
\hline WT pol & $40.1 \pm 1.45^{\mathrm{a}}$ & $43.0 \pm 2.53^{\mathrm{a}}$ & $51.3 \pm 3.29^{\mathrm{a}}$ & $0.58 \pm 0.034^{\mathrm{b}}$ \\
\hline $4-17$ & $42.0 \pm 2.22^{\mathrm{a}}$ & $53.4 \pm 4.46^{\mathrm{bc}}$ & $61.4 \pm 4.24^{\mathrm{b}}$ & $0.51 \pm 0.072^{\mathrm{ab}}$ \\
\hline $4-23$ & $40.3 \pm 2.28^{\mathrm{a}}$ & $54.0 \pm 3.67^{\mathrm{bc}}$ & $60.7 \pm 4.76^{\mathrm{b}}$ & $0.47 \pm 0.030^{\mathrm{a}}$ \\
\hline $4-25$ & $40.4 \pm 1.87^{\mathrm{a}}$ & $53.9 \pm 4.14^{\mathrm{bc}}$ & $60.3 \pm 4.83^{\mathrm{b}}$ & $0.47 \pm 0.035^{\mathrm{a}}$ \\
\hline $6-10$ & $39.3 \pm 1.09^{\mathrm{a}}$ & $52.0 \pm 2.18^{\mathrm{b}}$ & $58.2 \pm 1.61^{\mathrm{b}}$ & $0.46 \pm 0.045^{\mathrm{a}}$ \\
\hline $6-18$ & $40.2 \pm 3.11^{\mathrm{a}}$ & $54.0 \pm 1.91^{\mathrm{bc}}$ & $60.7 \pm 3.86^{\mathrm{b}}$ & $0.47 \pm 0.071^{\mathrm{a}}$ \\
\hline iaa9-3 & $40.4 \pm 1.24^{\mathrm{a}}$ & $57.0 \pm 2.80^{\mathrm{c}}$ & $63.6 \pm 2.58^{\mathrm{b}}$ & $0.45 \pm 0.039^{\mathrm{a}}$ \\
\hline
\end{tabular}

Table 3. Color index ( $\mathrm{L}^{*}, \mathrm{a}^{*}$, chroma, and hue) of mature fruits. Each data point represents the mean \pm standard deviation ( $n=20$ except $n=8$ of 6 lines). Different letters denote significant differences between factors according to Tukey's HSD test at $\mathrm{p}<0.01$.

Downregulation of SIIAA9 by the two promoters presented facultative parthenocarpic fruit formation without abnormal vegetative phenotype in transgenic tomato lines.

\section{Methods}

Plant materials and growth conditions. The tomato (Solanum lycopersicum L.) dwarf cultivar 'MicroTom' was used as the background for all the plant materials used in this study. Seeds were placed on filter paper with deionized water for 7 days at $25^{\circ} \mathrm{C}$. Germinated seeds were transplanted onto rockwool $(75 \times 75 \times 65 \mathrm{~mm}$; Grodan), irrigated with a nutrient solution (Otsuka Chemical) with an electrical conductivity (EC) of $1.8 \mathrm{dS} \mathrm{m}^{-1}$, and incubated under $16 \mathrm{~h} \mathrm{light} / 8 \mathrm{~h}$ dark conditions with fluorescent light at $300 \mu \mathrm{mol} \mathrm{m} \mathrm{m}^{-2} \mathrm{~s}^{-1}$ and a temperature of $25^{\circ} \mathrm{C}$. For the preparation of unpollinated or pollinated ovaries, flower buds were emasculated one day before anthesis or pollinated at anthesis. For 2,4-D-treated ovaries, used as a parthenocarpic fruit control induced by auxin traeatment ${ }^{11}$, the buds were emasculated one day before anthesis, and $4 \mu \mathrm{l}$ of 2,4 -dichlorophenoxyacetic acid (2,4-D) (Sigma-Aldrich) solution containing $20 \mathrm{ng}$ of $2,4-\mathrm{D}, 5 \%$ ethanol and $0.1 \%$ Tween 20 was applied to them at anthesis. In the fruit yield test, all the flowers at the anthesis stage on 50-day-old plants were pollinated or emasculated for 4 weeks.

DNA and RNA extraction and cDNA synthesis. Genomic DNA and total RNA were extracted using a DNeasy or RNeasy plant mini kit (Qiagen) according to the manufacturer's instructions. Total RNA was treated with a DNA-free RNA kit (Zymo Research) to eliminate DNA contamination. First-strand cDNA was synthesized from $1 \mu \mathrm{g}$ of total RNA using the PrimeScript II 1st strand cDNA Synthesis Kit (Takara-bio) and oligo dT primers. The synthesized cDNA was subjected to PCR to confirm genomic DNA-free cDNA with a set of SGN-U314153 (CAC) gene primers: forward, CCTCCGTTGTGATGTAACTGG, and reverse, ATTGGTGGAAAGTAACATCATCG ${ }^{44}$.

Vector construction and tomato transformation. To obtain the promoter region and SlIAA9 fragments, the genomic DNA or cDNA from the ovaries was amplified in $50 \mu \mathrm{l}$ of PCR mixture with $5 \mu \mathrm{l}$ of 10x buffer, $5 \mu \mathrm{l}$ of $2 \mathrm{mM}$ dNTPs, $1 \mathrm{U}$ of KOD Plus Neo (Toyobo), and $1 \mu \mathrm{l}$ of $10 \mu \mathrm{M}$ primers (Supplementary Table S1). The thermal cycling procedure consisted of $5 \mathrm{~min}$ at $98^{\circ} \mathrm{C}, 28$ cycles of amplification consisting of denaturation for $30 \mathrm{~s}$ at $98^{\circ} \mathrm{C}$, annealing for $30 \mathrm{~s}$ at $60^{\circ} \mathrm{C}$, and extension for $1 \mathrm{~min}$ at $68^{\circ} \mathrm{C}$, and a final extension at $68^{\circ} \mathrm{C}$ for $3 \mathrm{~min}$. For the promoter:GUS assay, promoter amplicons with HindIII $\left(5^{\prime}\right)$ and SalI $\left(3^{\prime}\right)$ restriction sites for Solyc03g007780 or with SalI ( $\left.5^{\prime}\right)$ and BamHI ( $\left.3^{\prime}\right)$ restriction sites for Solyc02g067760 were cloned into the pBI101-GUS vector. For the RNAi vector, an amplified promoter with Avr2 (5') and Xho1 (3') was inserted into the pBI-sense, antisense gateway vector (Inplanta Innovations) instead of P35S. Subsequently, $715 \mathrm{bp}$ SIIAA9 amplicons were cloned into the $\mathrm{pCR} 8 / \mathrm{GW} / \mathrm{TOPO}$ vector and inserted into the $\mathrm{pBI}$-sense, antisense gateway vector using Gateway LR Clonase (Thermo Fisher). The vector construct used in this study is shown in Supplementary Fig. S1.

Transgenic tomato production was conducted by Agrobacterium-mediated transformation according to a method previously described ${ }^{45}$. The transgenic lines were subjected to PCR using promoter and gene-specific primer sets and a Southern blot analysis to find the homozygous-independent lines.

Quantitative reverse transcription PCR. The expression levels of the genes were assessed by quantitative reverse transcription PCR (qRT-PCR) with a Dice Real-Time thermal cycler and SYBR Premix Ex Taq II following the manufacturer's protocol (Takara-bio). Diluted cDNA was used as a template in $25 \mu \mathrm{l}$ of PCR-amplification reaction mixture containing $12.5 \mu \mathrm{l}$ of SYBR Premix Ex Taq II (Takara-bio) and $1 \mu \mathrm{l}$ of the $10 \mu \mathrm{M}$ primer set. A dissociation curve analysis was also performed to confirm primer compatibility. The relative expression of the genes of interest was measured by the standard curve method with three biological replicates. SAND was used as a reference gene ${ }^{44}$. The primer set used for qRT-PCR is described in Supplementary Table S2.

GUS and histological assay. Histochemical ß-glucuronidase (GUS) analysis was performed with 5-bromo-4-chloro-3-indolyl-b-D-glucuronide (X-Gluc) using a previously described method, with a slight modification: phosphate buffer ( $\mathrm{pH}$ of 8.0 ) and $20 \%$ methanol $^{35,36,38}$. The tissues were incubated in the GUS staining solution at room temperature for $16 \mathrm{~h}$, followed by washing with $70 \%$ ethanol to eliminate chlorophyll. Paraffin sectioning was performed according to previously described methods ${ }^{46}$. 
Fruit characteristic analysis. For fruit analysis, twenty flowers per plant were emasculated or pollinated, and six fruits per plant were maintained for the experiment. Forty-eight-day-old fruits were subjected to color and weight measurements and stored at $-80^{\circ} \mathrm{C}$ for further experiments. The color was rated on the middle surface of the fruits with a Minolta Color Reader CR-10 (Konicaminolta). The color parameters describing lightness indicate the range from black $(0)$ to white $(100)\left(\mathrm{L}^{*}\right)$ and the color direction on the red to green scale $\left(\mathrm{a}^{*}\right)$ and on the yellow to blue scale $\left(b^{*}\right)$. The chroma (color saturation) was calculated as $\left(a^{* 2}+b^{* 2}\right)^{1 / 2}$. The hue (h, term used for the classification of red, yellow, blue, and green) was measured by taking the $\arctan (\mathrm{b} / \mathrm{a})$.

Frozen fruits were ground into a fine power and used to measure the total soluble solids (TSS), pH, titratable acidity (TA), and $\beta$-carotene and lycopene contents. The TSS was measured using a PAL-J refractometer (Atago). The $\mathrm{pH}$ and TA were analyzed using $1 \mathrm{~g}$ of fruit powder homogenized into $10 \mathrm{ml}$ of distilled water according to a previously described method ${ }^{47}$. Oxalic acid was used as a standard for the titrant calculation. The $\beta$-carotene and lycopene contents were measured and calculated according to a previously described method ${ }^{48}$. Supernatant from the extract of $300 \mathrm{mg}$ of fruit powder with $3 \mathrm{~mL}$ of acetone/hexane $(4: 6, \mathrm{v} / \mathrm{v})$ was tested for its absorption using a Beckman DU 640 UV/Vis spectrophotometer (Beckman Coulter). The $\beta$-carotene $\left(\mathrm{C}_{\mathrm{CAR}}\right)$ and lycopene $\left(\mathrm{C}_{\mathrm{LYC}}\right)$ concentrations were calculated using the following equations:

$$
\begin{aligned}
\mathrm{C}_{\text {CAR }}= & 0.216\left(\mathrm{~A}_{663}\right)-1.22\left(\mathrm{~A}_{645}\right) \\
& -0.304\left(\mathrm{~A}_{505}\right)+0.452\left(\mathrm{~A}_{453}\right) \\
\mathrm{C}_{\mathrm{LYC}}= & -0.04584\left(\mathrm{~A}_{663}\right)+0.204\left(\mathrm{~A}_{645}\right) \\
& +0.372\left(\mathrm{~A}_{505}\right)-0.0806\left(\mathrm{~A}_{453}\right)
\end{aligned}
$$

Received: 23 May 2019; Accepted: 27 November 2019;

Published online: 11 December 2019

\section{References}

1. Barry, C. S. \& Giovannoni, J. J. Ethylene and fruit ripening. J. Plant Growth Regul. 26, 143-159 (2007).

2. de Jong, M., Mariani, C. \& Vriezen, W. H. The role of auxin and gibberellin in tomato fruit set. J. Exp. Bot. 60, 1523-1532 (2009).

3. Gillaspy, G., Ben-David, H. \& Gruissem, W. Fruits: a developmental perspective. Plant Cell 5, 1439-1451 (1993).

4. Giovannoni, J. J. Genetic regulation of fruit development and ripening. Plant Cell 16, S170-S180 (2004).

5. Crane, J. C. The role of hormones in fruit set and development development. HortScience 4, 108-111 (1969).

6. Jones, J. B. Jr. Tomato plant culture: in the field, greenhouse, and home garden. (Boca Raton, USA: CRC Press, 2007).

7. Peet, M. M. \& Bartholemew, M. Effect of night temperature on pollen characteristics, growth, and fruit set in tomato. J. Am. Soc. Hortic. 121, 514-519 (1996).

8. Peet, M. M., Willits, D. H. \& Gardner, R. Response of ovule development and post-pollen production processes in male-sterile tomatoes to chronic, sub-acute high temperature stress. J. Exp. Bot. 48, 101-111 (1997).

9. Abad, M. \& Monteiro, A. A. The use of auxins for the production of greenhouse tomatoes in mild - winter conditions: a review. Scientia Horticulturae 38, 167-192 (1989).

10. Gustafson, F. G. Parthenocarpy: natural and artificial. Bot. Rev. 8, 599-654 (1942).

11. Serrani, J. C., Fos, M., Atarés, A. \& García-Martínez, J. L. Effect of gibberellin and auxin on parthenocarpic fruit growth induction in the cv Micro-Tom of tomato. J. Plant Growth Regul. 26, 211-221 (2007).

12. Fos, M., Nuez, F. \& García-Martínez, J. L. The gene pat-2, which induces natural parthenocarpy, alters the gibberellin content in unpollinated tomato ovaries. Plant Physiol. 122, 471-480 (2000).

13. Ficcadenti, N. et al. Genetic engineering of parthenocarpic fruit development in tomato. Mol. Breed. 5, 463-470 (1999).

14. Pandolfini, T., Rotino, G. L., Camerini, S., Defez, R. \& Spena, A. Optimisation of transgene action at the post-transcriptional level: high quality parthenocarpic fruits in industrial tomatoes. BMC Biotechnol. 2, 1 (2002).

15. Rotino, G. L., Perri, E., Zottini, M., Sommer, H. \& Spena, A. Genetic engineering of parthenocarpic plants. Nat. Biotechnol. 15, 1398-1401 (1997).

16. Pandolfini, T., Molesini, B. \& Spena, A. Molecular dissection of the role of auxin in fruit initiation. Trends Plant Sci. 12, 327-9 (2007).

17. Saito et al. TOMATOMA: a novel tomato mutant database distributing Micro-Tom mutant collections. Plant Cell Physiol. 52, 283-296 (2011).

18. Wang et al. The tomato Aux/IAA transcription factor IAA9 is involved in fruit development and leaf morphogenesis. Plant Cell 17, 2676-92 (2005)

19. Mazzucato et al. A TILLING allele of the tomato Aux/IAA9 gene offers new insights into fruit set mechanisms and perspectives for breeding seedless tomatoes. Mol. Breed. 35, 22 (2015).

20. Mignolli et al. Induction of gibberellin 20-oxidases and repression of gibberellin $2 \beta$-oxidases in unfertilized ovaries of entire tomato mutant, leads to accumulation of active gibberellins and parthenocarpic fruit formation. Plant Growth Regul. 75, 415-425 (2015).

21. Hull, R., Convey, S. N. \& Dale, P. Genetically modified plants and the 35 S promoter: assessing the risks and enhancing the debate. Microb. Ecol. Health Dis. 12, 1-5 (2000).

22. Martí, C. et al. Silencing of DELLA induces facultative parthenocarpy in tomato fruits. Plant J. 52, 865-876 (2007).

23. Jeong, H.-J., Choi, J. Y., Shin, H. Y., Bae, J.-M. \& Shin, J. S. Seed-specific expression of seven Arabidopsis promoters. Gene 553, 17-23 (2014).

24. Pan, Y. et al. Spatial and temporal activity of the foxtail millet (Setaria italica) seed-specific promoter pF128. Planta 57-67 (2014).

25. Sunkara, S., Bhatnagar-Mathur, P. \& Sharma, K. K. Isolation and functional characterization of a novel seed-specific promoter region from peanut. Appl. Biochem. Biotechnol. 172, 325-339 (2014).

26. Jiang, W. et al. Molecular cloning and characterization of a trichome-specific promoter of artemisinic aldehyde $\Delta 11(13)$ reductase (DBR2) in artemisia annua. Plant Mol. Biol. Report. 32, 82-91 (2014).

27. Spyropoulou, Ea, Haring, Ma \& Schuurink, R. C. Expression of terpenoids 1, a glandular trichome-specific transcription factor from tomato that activates the terpene synthase 5 promoter. Plant Mol. Biol. 84, 345-357 (2014).

28. Ha, J.-H. et al. The laccase promoter of potato confers strong tuber-specific expression in transgenic plants. Plant Cell, Tissue Organ Cult. 120, 57-68 (2015).

29. Chen, L. et al. GmPRP2 promoter drives root-preferential expression in transgenic Arabidopsis and soybean hairy roots. BMC Plant Biol. 14, 245 (2014).

30. Chen, L. et al. The characterization of GmTIP, a root-specific gene from soybean, and the expression analysis of its promoter. Plant Cell, Tissue Organ Cult. 121, 259-274 (2015). 
31. Oo, M. M. et al. Evaluation of rice promoters conferring pollen-specific expression in a heterologous system, Arabidopsis. Plant Reprod. 27, 47-58 (2014).

32. Azuma, M. et al. The petal-specific InMYB1 promoter functions by recognizing petaloid cells. Plant Cell Physiol. 57, 580-587 (2016).

33. Ezura, K. et al. Genome-wide identification of pistil-specific genes expressed during fruit set initiation in tomato (Solanum lycopersicum). Plos One. 12 (2017).

34. Pattison, R. J. et al. Comprehensive tissue-specific transcriptome analysis reveals distinct regulatory programs during early tomato fruit development. Plant Physiol. 168, 1684-1701 (2015).

35. Hodal, L., Bochardt, A., Nielsen, J. E., Mattsson, O. \& Okkels, F. T. Detection, expression and specific elimination of endogenous $\beta$-glucuronidase activity in transgenic and non-transgenic plants. Plant Sci. 87, 115-122 (1992).

36. Kosugi, S., Ohashi, Y., Nakajima, K. \& Ara, Y. An improved assay for $\beta$-glucuronidase in transformed cells: methanol almost completely supresses a putative endogenous $\beta$-glucuronidase activity. Plant Sci. 70, 133-140 (1990).

37. Hu, C. Y. et al. Intrinsic GUS-like activities in seed plants. Plant Cell Rep. 9, 1-5 (1990).

38. Jefferson, Ra, Kavanagh, Ta \& Bevan, M. W. GUS fusions: beta-glucuronidase as a sensitive and versatile gene fusion marker in higher plants. EMBO J. 6, 3901-3907 (1987).

39. Wang et al. Regulatory features underlying pollination-dependent and -independent tomato fruit set revealed by transcript and primary metabolite profiling. Plant Cell 21, 1428-1452 (2009).

40. Anthon, G. E., LeStrange, M. \& Barrett, D. M. Changes in $\mathrm{pH}$, acids, sugars and other quality parameters during extended vine holding of ripe processing tomatoes. J. Sci. Food Agric. 91, 1175-1181 (2011).

41. Kabelka, E., Yang, W. \& Francis, D. Improved tomato fruit color within an inbred backcross line derived from Lycopersicon esculentum and L. hirsutum involves the interaction of loci. J. Am. Soc. Hortic. Sci. 129, 250-257 (2004).

42. Carrillo-López, A. \& Yahia, E. M. Changes in color-related compounds in tomato fruit exocarp and mesocarp during ripening using HPLC-APcI+-mass Spectrometry. J. Food Sci. Technol. 51, 2720-2726 (2014).

43. Shi et al. Lycopene degradation and isomerization in tomato dehydration. Food Res.Int. 32, 15-21 (1999).

44. Expósito-Rodríguez, M., Borges, A. A., Borges-Pérez, A. \& Pérez, J. A. Selection of internal control genes for quantitative real-time RT-PCR studies during tomato development process. BMC Plant Biol. 8, 131 (2008).

45. Sun, H.-J., Uchii, S., Watanabe, S. \& Ezura, H. A highly efficient transformation protocol for Micro-Tom, a model cultivar for tomato functional genomics. Plant Cell Physiol. 47, 426-31 (2006).

46. Chusreeaeom, K. et al. A novel tomato mutant, Solanum lycopersicum elongated fruit1 (Slelf1), exhibits an elongated fruit shape caused by increased cell layers in the proximal region of the ovary. Molecular Genetics and Genomics. 289, 399-409 (2014).

47. Dalal K., Salunkhe D. K., Boe A. A. \& Olson L. E. Physiological and biochemical changes tomato fruit (Lycopersicon esculentum Mill.). J. Food Sci. (1965).

48. Nagata, Y. \& Yamashita, I. Simple method for simultaneous determination of chlorophyll and carotenoids in tomato fruit. J. Japan Soc. Food Sci. Technol. 39, 925-928 (1992).

\section{Acknowledgements}

This work was funded by the Science and Technology Research Promotion Program for Agriculture, Forestry, Fisheries and Food Industry, Japan, http://www.affrc.maff.go.jp/index.htm, grant no. 26013 A to H.E.

\section{Author contributions}

T.A. and H.E. managed and organized the project. J.K. and H.E. conceived and designed the experiments. J.K., K.E. and J.L. conducted the experiments. K.E. and T.A. contributed reagents or analytical tools. J.K. and J.L. analyzed the data. J.K. and H.E. wrote the manuscript.

\section{Competing interests}

The authors declare no competing interests.

\section{Additional information}

Supplementary information is available for this paper at https://doi.org/10.1038/s41598-019-55400-7.

Correspondence and requests for materials should be addressed to H.E.

Reprints and permissions information is available at www.nature.com/reprints.

Publisher's note Springer Nature remains neutral with regard to jurisdictional claims in published maps and institutional affiliations.

Open Access This article is licensed under a Creative Commons Attribution 4.0 International License, which permits use, sharing, adaptation, distribution and reproduction in any medium or format, as long as you give appropriate credit to the original author(s) and the source, provide a link to the Creative Commons license, and indicate if changes were made. The images or other third party material in this article are included in the article's Creative Commons license, unless indicated otherwise in a credit line to the material. If material is not included in the article's Creative Commons license and your intended use is not permitted by statutory regulation or exceeds the permitted use, you will need to obtain permission directly from the copyright holder. To view a copy of this license, visit http://creativecommons.org/licenses/by/4.0/.

(C) The Author(s) 2019 